\title{
Long-term external and internal irradiation of inhabitants in an area highly contaminated by the Chernobyl accident
}

\author{
C. Thornberg, S. Mattsson, T. Jesko ${ }^{1}$, I. Zvonova ${ }^{1}$, E. Wallström ${ }^{2}$ and R. Vesanen ${ }^{2}$ \\ Department of Radiation Physics, Lund University, Malmö University Hospital, \\ 20502 Malmö, Sweden \\ ${ }^{1}$ Institute of Radiation Hygiene, Mira St. 8, St. Petersburg, Russia \\ ${ }^{2}$ Department of Radiation Physics, Göteborg University, Sahlgren University Hospital, \\ 41345 Göteborg, Sweden
}

\begin{abstract}
From 1990 to 1998 , estimations of the effective dose from external and internal irradiation due to ${ }^{137} \mathrm{Cs}$ and ${ }^{134} \mathrm{Cs}$ were carried out for inhabitants in rural villages in the Bryansk region, Russia, highly contaminated due to the Chemobyl accident in 1986. Yearly expeditions were conducted in autumn. The external effective dose was estimated from measurements with thermoluminescent (TL)-dosemeters worn by the participants during one month each year. The internal effective dose was estimated from measurements of the urinary concentration of caesium radionuclides, together with measurements of the body content using a portable detector. The mean effective dose from extemal and internal irradiation varied between 1.2 and $2.5 \mathrm{mSv}$ per year between 1990 and 1998 . The total mean effective dose decreased, on average, $7 \%$ per year, while the mean external dose decreased by $15 \%$ per year. The dose rate from internal irradiation decreased more slowly than the dose rate from external irradiation, showing large variations from year to year depending to a great extent on dietary habits. The contribution from the external dose to the total dose was between $50-70 \%$, depending on the village. The cumulated effective dose for the 70-year period after the accident was calculated to be $100 \mathrm{mSv}$ with the assumption that both internal and external dose will decrease by $2 \%$ per year.
\end{abstract}

\section{INTRODUCTION}

The Chernobyl nuclear power plant accident in 1986 led to a high level of radioactive contamination in the Bryansk area in Russia, some $150-250 \mathrm{~km}$ north-northeast of the nuclear power plant. An area of approximately $2,400 \mathrm{~km}^{2}$, having a population of about 112,000 , was contaminated with ${ }^{137} \mathrm{Cs}$, resulting in a deposition greater than $0.55 \mathrm{MBq} \mathrm{m^{-2 }}$ which meant that they were designated "controlled areas", (CA) [1]. During some years after the accident countermeasures, such as relocation of inhabitants (in 1986 and in 1990), provision of uncontaminated foodstuffs and decontamination of a number of villages, were undertaken in certain areas. Since the time of the accident, people living in the contaminated areas have been exposed to both external and internal irradiation mainly from ${ }^{137} \mathrm{Cs}$. In 1990 , a joint NordicRussian programme was established to assess the effective doses to individuals in a number of villages in a western district of the Bryansk area around the town of Novozybkov. Yearly expeditions were carried out between 1990 and 1998, and the long-term changes in both internal and external irradiation were investigated as well as different methods of estimating internal and external effective dose [2-6].

In this work the irradiation in terms of the effective dose to the inhabitants in the villages by external as well as internal radiation from ${ }^{137} \mathrm{Cs}$ is further analysed, as well as the relation between internal and external effective dose during 1986-2056, employing our own measurements and published data.

\section{MATERIAL AND METHODS}

\subsection{Location and participants}

The villages investigated, with reported ${ }^{137} \mathrm{Cs}$ depositions of between 0.9 and $2.7 \mathrm{MBq} \mathrm{m}^{-2}$ are situated in a rural area in the south-western part of Russia. Each village has a typical population of 300-600 inhabitants, whose principal occupation is agriculture on state owned or private farms. Measurements were performed in September or October each year from 1990 to 1998. The volunteer participants were between 2 and 80 years old and lived in either brick or wooden houses. Many of the young participants were school children. 
Due to rainfall when the radioactive cloud from Chernobyl passed over the area, the deposition was high and its pattern very inhomogeneous. This means that the deposition can vary by a factor of up to 10 , even over small areas. Various types of countermeasures were applied directly after the accident, and the villages were decontaminated to various extents in 1989, usually by removing the topsoil around kindergartens, schools and other public places as well as along the roads, and then covering the ground with gravel or asphalt.

\subsection{Assessment of body burden of caesium radionuclides}

In vivo measurements of the body burden of ${ }^{137} \mathrm{Cs}$ and ${ }^{134} \mathrm{Cs}$ were carried out on the inhabitants of five different villages with the additional collection of urine samples from a sub-group of the individuals. Estimations of the body burden of ${ }^{137} \mathrm{Cs}$ in inhabitants from the various villages by means of urine samples has been performed yearly between 1991 and 1998 [7-9]. Single urine samples (20-100 mll) were collected from around 50 individuals at the time of the whole-body measurements. A number of samples were analysed by means. of gamma spectrometry at The Branch of Institute of Radiation Hygiene in Novozybkov, Russia, using a scintillation spectrometer (SGS-200) before being transported to Sweden, where the concentration of ${ }^{137} \mathrm{Cs}$ was measured at the Department of Radiation Physics either in Malmo (HPGe, 35\% relative efficiency at $1.33 \mathrm{MeV}$ ) or in Göteborg $(125 \mathrm{~mm}(\varnothing) \times 100 \mathrm{~mm} \mathrm{NaI(Tl})$ ). The statistical uncertainty ( $1 \mathrm{SD}$ ) in the urine measurements was estimated to be less than $5 \%$ for all detector systems.

A $\mathrm{NaI}(\mathrm{Tl})$ detector $(63 \mathrm{~mm}(\varnothing) \times 63 \mathrm{~mm})$ and a single-channel scintillation spectrometer (RFT. 20046, Robotron, Germany) were used to perform direct in vivo determination of the ${ }^{137,134} \mathrm{Cs}$ body burden in about 500 inhabitants every year from 1991 to $1998[3,5,10]$. The measurements were carried out with the individual in a sitting position, bending over the detector which was resting in the lap directed towards the abdomen. The calibration method for ${ }^{137} \mathrm{Cs}$ and ${ }^{134} \mathrm{Cs}$ measurements in vivo was developed in a study with volunteers who ingested known amounts of the radionuclides, and verified with measurements of the same persons in a well-shielded, stationary whole-body counter [11]. For a normal background (close to natural levels), the minimum detectable body burden was estimated to be $1-2 \mathrm{kBq}$. The coefficient of variation (CV) at that level was estimated to be $\pm 50 \%$, and at a body burden of $10 \mathrm{kBg}$ it was estimated to be $20 \%$.

\subsection{Measurements of external irradiation}

Thermoluminescent (TL) dosemeters, consisting of $3 \times 3 \times 0.9 \mathrm{~mm}^{3}$ LiF chips (Harshaw TLD 100), were used to assess the absorbed dose to individuals in six villages from external irradiation in their environment. The dosemeters were transported to Russia in a lead container with $10 \mathrm{~mm}$ thick walls, together with reference dosemeters which were stored in the container during the whole process in order to estimate the background signal accumulated during travelling and storage. The LiF chips were mounted in a polyethylene dosemeter holder and worn by the participants on a cord around the neck fora period of one month in September or October. Upon collection from the participants, the dosemeters were put back into the lead container and sent to Sweden for evaluation.

\subsection{Calculation of effective dose}

The annual effective dose from internal exposure was calculated using the measurements of the body content of ${ }^{137} \mathrm{Cs}$ and ${ }^{134} \mathrm{Cs}$ and the age-dependent metabolic and dosimetric parameters for caesium 
radionuclides obtained from ICRP publications 56 and $67[12,13]$. The annual effective dose for an individual was calculated according to the equation:

$$
E_{\text {int }}=r_{\text {sum }}(m) \cdot \mathrm{A} / \mathrm{m} \mathrm{mv}
$$

where $r_{\text {sum }}$ is the dose rate coefficient $\left(\mathrm{mSv} / \mathrm{y}\right.$ per $\mathrm{kBq} / \mathrm{kg}$ ) for the total content of ${ }^{137} \mathrm{Cs}$ and ${ }^{134} \mathrm{Cs}$ in a person with body mass $m(\mathrm{~kg})$, as presented in [3], but recalculated using updated dose coefficients from ICRP publication 67 [13]. The dose rate coefficients for people of different body masses were estimated from values of the committed effective dose per unit intake at a certain age [12]. $A$ is the measured sum of the activities of ${ }^{137} \mathrm{Cs}$ and ${ }^{134} \mathrm{Cs}$ in the body $(\mathrm{kBq})$. The yearly effective dose will be somewhat overestimated for certain individuals, since our measurements were carried out in the autumn, when the body burden of ${ }^{137} \mathrm{Cs}$ has been reported to be $60 \%-100 \%$ higher than during the spring and summer, mainly due to an increased intake of forest products.

The effective dose from external radiation, $E_{e x t}$, was calculated according to the equation:

$$
E_{\text {ext }}=D_{\text {surface }} \cdot\left(K_{\text {air }} / D_{\text {surface }}\right) \cdot\left(E / K_{\text {air }}\right) \quad S v
$$

where $D_{\text {surface }}$ is the absorbed dose to the body surface, as measured with the dosemeter, and $K_{\text {air }}$ is the air kerma. For adults ( $>15$ years), we used the values of $1.11 \mathrm{~Gy} / \mathrm{Gy}$ for the ratio $K_{\text {air }} / D_{\text {surface }}[14]$ and 0.83 $S v /$ Gy for the ratio $E / K_{\text {air }}[15]$. Thus, the product of the two conversion factors, $E / D_{\text {surface }}$ was $0.92 \mathrm{~Sv} / \mathrm{Gy}$. For school children we multiplied the dosemeter reading by $0.95 \mathrm{~Sv} / \mathrm{Gy}$ to obtain the effective dose. The same values were used during the whole study period. The value of the effective dose per month (September-October) was multiplied by 12 and by 0.94 [16] in order to obtain the annual effective dose, corrected for snow cover during winter-time.

\section{RESULTS AND DISCUSSION}

The effective dose from internal irradiation did not show any clear temporal trends during the period of the study. The activity concentration in milk has been found to decrease with a half-time of 10 years in the area $[17,18]$ in the remote period after the accident, and together with the fact that the activity concentration in forest products decreases essentially with the physical half-life of ${ }^{137} \mathrm{Cs}$, the slow decrease in body burden is understandable, since this is the parameter with the greatest influence on the body burden of ${ }^{137} \mathrm{Cs}$ today.

The mean effective dose from external and internal irradiation due to ${ }^{137} \mathrm{Cs}$ and ${ }^{134} \mathrm{Cs}$ for both children and adults varied between 1.2 and $2.5 \mathrm{mSv}$ between 1991 and 1998, see Fig. 1. A pre-Chernobyl background of $45 \mu \mathrm{Sv}$ per month [6] was subtracted from the external dose values. Although there is no such temporal trend in the internal effective dose levels as for the external dose during this period, the total effective dose from both internal and external radiation decreased with time, except in 1998. The total mean effective dose decreased, on average, by $7 \%$ per year, while the mean external dose decreased by $15 \%$ per year. Since the dose rate from internal exposure appears to be decreasing more slowly than the dose rate from external radiation, its contribution to the total effective dose from ${ }^{137} \mathrm{Cs}$ will become more important in the years to come. 


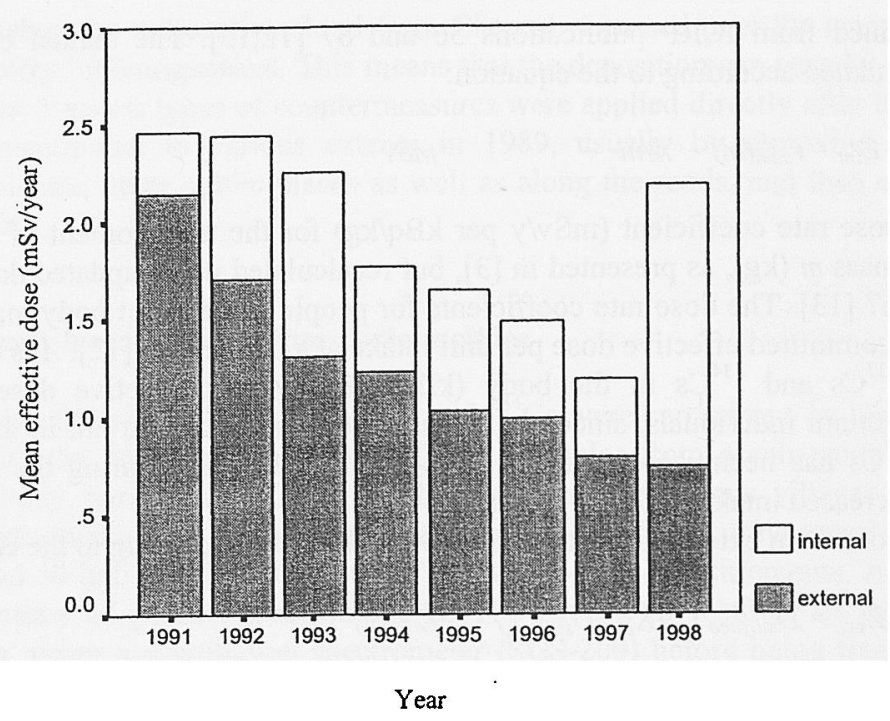

Figure. 1. Mean relative contributions from annual internal and external effective dose from 1991 to 1998.

In Fig. 2, the mean ratio of the external effective dose to the total (internal plus external) effective dose is presented as a function of deposition. Ratios for the deposition below $0.5 \mathrm{MBq} \mathrm{m}^{-2}$ was obtained from UNSCEAR [19]. It is interesting to note the trend of higher relative contribution from external irradiation with higher deposition. In areas with high deposition, a number of countermeasures aimed at reducing the internal effective dose have been employed. This may have caused the internal doses to become relatively lower compared with external doses, for which countermeasures such as decontamination did not reduce the doses as efficiently.

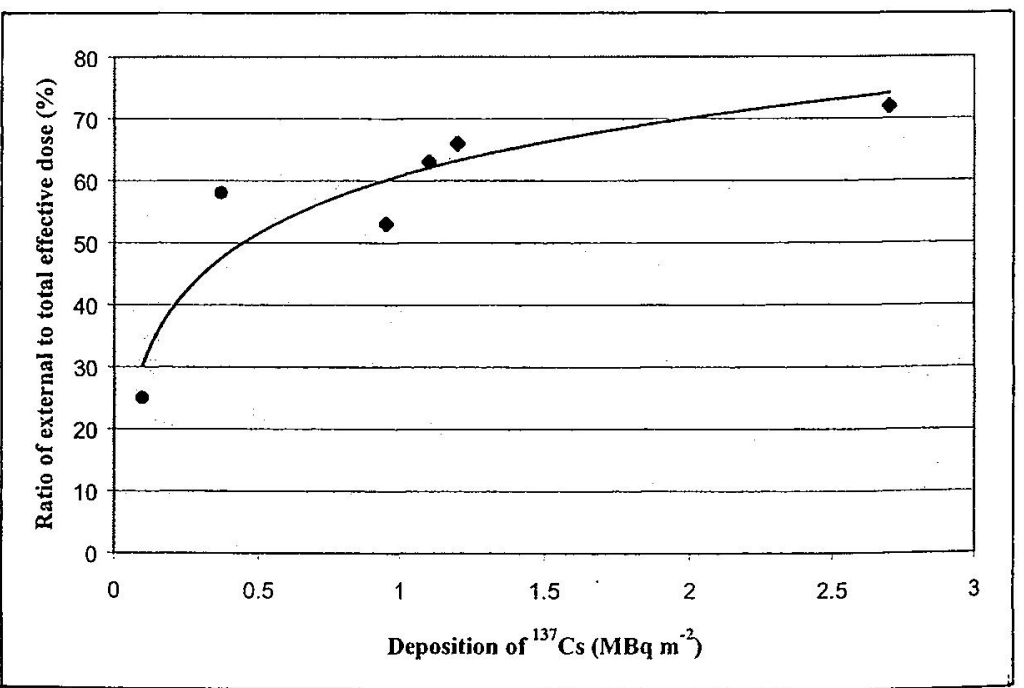

Figure.2. The ratio of external to total effective dose for different deposition levels in rural areas in Russia. The symbols indicate measured values presented in this work $(\bullet)$ and values obtained from UNSCEAR [19] $(\bullet)$. 
By using published data for the years 1986-1989 [20,21] together with annual mean values for the external and internal effective doses obtained from our own study the cumulated total effective dose between 1986 and 2056 (a 70-year period) was predicted assuming various decrease rates for both internal and external effective dose after 1998, Table 1.

Table 1. The cumulated effective dose between 1986 and 2056 for three different scenarios after 1998. In scenario 1, both the external and the internal effective doses were assumed to decrease with arate of $2 \%$ per year (physical decay of ${ }^{137} \mathrm{Cs}$ ) after 1998. In scenario 2, the external and internal effective doses were assumed to have a rate of decrease of $8 \%$ and $2 \%$ per year, respectively, and in scenario $3,15 \%$ and $4 \%$ per year, respectively, after 1998 .

\begin{tabular}{lccc}
\hline & \multicolumn{3}{c}{ Cumulated effective dose (mSv) } \\
\cline { 2 - 4 } & External & Internal & Total \\
\hline Scenario 1 & 65 & 35 & 100 \\
Scenario 2 & 50 & 35 & 85 \\
Scenario 3 & 45 & 25 & 70 \\
\hline
\end{tabular}

The cumulated mean effective dose was estimated to be on average $100 \mathrm{mSv}$ when making the conservative assumption of a reduction rate after 1998 of $2 \%$ per year both for internal and external irradiation. Assuming a more optimistic decrease rate of the effective dose where the external dose will decrease with the same rate as today (15\%), together with a $4 \%$ reduction in the internal dose after 1998 , gave a value of the cumulated effective dose of $70 \mathrm{mSv}$. However, this is not a likely scenario, since the decrease rate of the external irradiation is expected to slow down in the future, due to a slowing down in the migration of ${ }^{137} \mathrm{Cs}$ in the ground. Therefore the assumption of a decrease rate of the external effective dose of about $8 \%$ per year during the years to come is more likely to occur. Assuming a reduction rate after 1998 of $2 \%$ and $8 \%$ per year, for the internal and the external effective dose, respectively, gave a value of $85 \mathrm{mSv}$.

More than $50 \%$ of the effective dose was received before 1998 , hence the assumptions made in the prognosis for the future have no major influence on the cumulated effective dose. The cumulated effective dose from internal irradiation in the different scenarios was estimated to be $25-35 \mathrm{mSv}$. For comparison, a prognosis of the internal effective dose between 1986 and 2056 for the same area recently published by UNSCEAR [19], showed a figure of $32 \mathrm{mSv}$ per unit deposition of ${ }^{137} \mathrm{Cs}\left(\mathrm{MBq} \mathrm{m} \mathrm{m}^{-2}\right)$ in the $\mathrm{CA}$, presented together with a prognosis for the external effective dose of $65 \mathrm{mSv}$ per $\mathrm{MBq} \mathrm{m}^{-2}$ in rural areas.

\section{ACKNOWLEDGEMENTS}

This project was supported by the Swedish Radiation Protection Institute, SSI. We would like to especially thank all the participants in the villages studied, as well as Professor Mikhail Balonov, Institute of Radiation Hygiene in St Petersburg, for his support during the years.

\section{REFERENCES}

[1] Balonov, M.I.and Travnikova, I.G. Importance of diet and protective actions on internal dose from Cs radionuclides in inhabitants of the Chernobyl region. In: The Chernobyl Papers, Vol. 1, Doses to the Soviet Population and Early Health Effects Studies. Eds S.E. Mervin and M.I. Balonov (Research Enterprises, Richland, USA, 1993) pp. 127-166

[2] Erkin, V., Wallström, E., and Wöhni, T. Radiat. Prot. Dosim. 51(4) (1994) pp. 265-273

[3] Zvonova, I.A., Jesko, T.V., Balonov, M.I., Danilova, I.O., Wallström, E., Alpsten, M., Thornberg, C., and Mattsson, S. Radiat. Prot. Dosim. 62(4) (1995) pp. 213-221

[4] Wallström, E., Assessment of population radiation exposure after a nuclear reactor accident. Field studies in Russia and Sweden after Chernobyl. (Thesis, Department of Radiation Physics, Göteborg University, Göteborg, Sweden, 1998) ISBN 91-628-3221-1 
[5] Jesko, T., Zvonova, I., Balonov, M., Thomberg, C., Mattsson, S., Wallström, E., Vesanen, R., and Alpsten, M. Radiat. Prot. Dosim. 89(3-4) (2000), pp. 179-182

[6] Thornberg, C., Vesanen, R., Wallström, E., Zvonova, I., Jesko, T., Albinsson, J., Börjesson, J. and Mattsson, S. Long-term external radiation exposure of inhabitants in the western Bryansk region, Russia as a consequence of the Chernobyl accident. Accepted for publication in Radiat. Environ. Biophys. (2001) [7] Wallström, E., Thornberg, C., Erkin, V., Wöhni, T., Gulikov, V., Zvonova, I., Jesko, T., Alpsten, M., Balonov, M. and Mattsson, S. "Estimation of radiation doses to population groups in the Brjansk area, Russia following the Chernobyl accident." Proceedings of symposium - Environmental Impact of Radioactive Releases, Vienna, May 1995. IAEA-SM-339/96, (1995) pp. 413-420

[8] Rääf, C., Thornberg, C. and Mattsson, S. Appl. Radiat. Isotopes. 51(5) (1999) pp. 505-514

[9] Thornberg, C., Wallström, E., Zvonova, I., Jesko, T., Vesanen, R., Mattsson, S., Alpsten, M. and Balonov, M. Radiat. Prot. Dosim. 88(3) (2000) pp. 239-246

[10] Zvonova, I.A., Bruk, G.Ya., Kaidanovsky, G.N., Jesko, T.V. and Balonov, M.I. Radiat. Prot. Dosim. 89(3-4) (2000) pp. 173-178

[11] Kaidanovsky, G.N. and Dolgirev, E.I. Radiat. Prot. Dosim. 71(3) (1997) pp. 187-194

[12] International Commission on Radiological Protection. (1989) Age-dependent Doses to Members of the Public from Intakes of Radionuclides. ICRP Publication 56, Part 1; Ann. ICRP 20 (2), Oxford: Pergamon Press

[13] International Commission on Radiological Protection. (1993) Age-dependent doses to members of the public from intake of radionuclides: Part 2. Ingestion dose coefficients. ICRP Publication 67, Part 2. Ann. ICRP, 23(3/4)

[14] Jacob, P., Paretzke, H.G., Rosenbaum, H., Zankl, M. Health Phys. 54(6) (1988) pp.617-633

[15] Jacob, P., Paretzke, H.G., Rosenbaum, H., Zankl, M. Radiat. Prot. Dosim. 14 (1986) pp. 299-310.

[16] Jacob, P. and Likhtariev, I. (Editors) Final report. EUR 16541 EN, ISBN 92-8275207-0 Luxembourg (1996).

[17] Bruk, G., Shutov, V., Balonov, M., Basalaeva, L., and Kislov, M. Radiat. Prot. Dosim. 76, (1998) pp. $169-178$

[18] Balonov, M.I., Bruk, G.Ya., Zvonova, I.A., Pitkevich, V.A., Bratilova, A.A., Jesko, T.V., and Shutov, V.N. Radiat. Prot. Dosim. 92 (1-3) (2000) pp. 247-253

[19] United Nations. Sources and Effects of Ionising Radiation : United Nations Scientific Committee on the Effects of Atomic Radiation, (UNSCEAR), 2000 Report to the General Assembly, with scientific annexes. United Nations, New York. Vol. 1: Sources. - 654 s. ISBN 92-1-142238-8 (2000)

[20] Balonov, M.I. and Travnikova, I.G. Importance of diet and protective actions on internal dose from Cs radionuclides in inhabitants of the Chernobyl region. In: The Chernobyl Papers, Vol. 1, Doses to the Soviet Population and Early Health Effects Studies. Eds S.E. Mervin and M.I. Balonov (Research Enterprises, Richland, USA, 1993) pp. 127-166

[21] Shutov, V.N., Bruk, G.Y., Balonov, M.I., Parkhomenko, V.I. and Pavlov, I.Y. Cesium and strontium radionuclide migration in the agricultural ecosystem and estimation of internal doses to the population. In: The Chernobyl Papers, Vol. 1, Doses to the Soviet Population and Early Health Effects Studies. Eds S.E. Mervin and M.I. Balonov (Research Enterprises, Richland, USA, 1993) pp. 221-246 